\title{
A New Determination of the Atomic Weight of Zinc*
}

\author{
George Marinenko
}

\author{
Institute for Materials Research, National Bureau of Standards, Washington, D.C. 20234 \\ and
}

The American University, Washington, D.C. 20016

and

Robert T. Foley

The American University, Washington, D.C. 20016

\begin{abstract}
The atomic weight of zinc determined coulometrically for 5 metallic reference samples is $65.377 \pm$ 0.003 where the uncertainty figure is the 95 percent confidence interval for the mean plus an allowance for known possible sources of systematic error.

Key words: Atomic weight; coulometry; zinc, atomic weight.
\end{abstract}

\section{Introduction}

The presently accepted value for the atomic weight of zinc is $65.3_{7}[1,2] .{ }^{1}$ The above value is based primarily on $\mathrm{ZnCl}_{2} / 2 \mathrm{Ag}$ [3], $\mathrm{ZnCl}_{2} / 2 \mathrm{AgCl}$ [3], $\mathrm{ZnBr}_{2} / \mathrm{Zn}$ [4], and $\mathrm{ZnCl}_{2} / \mathrm{Zn}$ [5] combining weight ratios. Two mass spectrometric determinations of the isotopic abundances $[6,7]$ yield a significantly different value for the atomic weight of zinc-65.387. Since mass spectrometric measurements were carried out without the absolute calibration of the instruments the Commission recommended retaining the chemically determined value [8].

An electrochemical method for the determination of the electrochemical equivalent and the atomic weight of zinc has been utilized in this work, which will aid in narrowing down the existing uncertainty in this important constant.

The suitability of electrochemical methods for the determination of atomic weights was implied in the original work of Faraday. In 1833 he established that the law of definite proportions holds even when the chemical reactions are not carried out directly but are induced by the passage of electric current through the electrolysis cells [9]. The amount of chemical change produced at the electrodes of a cell is directly proportional to the quantity of charge passed.

Explicit utilization of Faraday's laws for the determination of atomic weights was recognized very

*This work was conducted in partial fulfillment of the requirements for $\mathrm{Ph} \mathrm{D}$. degree.

${ }^{1}$ Figures in brackets indicate the literature references at the end of this paper. early in the development of quantitative electrochemistry. Thus, for example, Laird and Hulett state [10]:

"Faraday's law, that a definite quantity of electricity is associated with one gram equivalent of any ion, is, as far as we know, strictly accurate, probably as accurate as the law of conservation of mass. There is evidence that not even as small a quantity of electricity as $10^{-16}$ coulomb passes from an electrolyte to an electrode without a corresponding chemical change taking place..."

Using electrolytic deposition of $\mathrm{Cd}$ in series with a silver coulometer, Laird and Hulett were able to obtain precise $\mathrm{Cd} / \mathrm{Ag}$ ratios, and assigning a value for the atomic weight of silver they were able to calculate the atomic weight of cadmium. A similar approach had been used by Gladstone and Hibbert earlier [11] for the determination of $\mathrm{Zn} / \mathrm{Ag}$ and $\mathrm{Zn} / \mathrm{Cu}$ ratios, and subsequently, the atomic weight of zinc. Unfortunately, we now know that silver deposition coulometers and copper coulometers, though precise for a given set of experimental conditions, are not very accurate due to the differences in the amount of occluded mother liquor in the deposit obtained in different laboratories. This aspect of silver deposition coulometers is discussed by Hamer [12]. A more direct approach to the determination of the electrochemical equivalent is through the use of absolute current and time measurements, employed by Craig and coworkers [13] in the determination of the electrochemical equivalent of silver and the faraday. The anodic silver coulometer obviates mother liquor occlusion errors but at the same time it requires tedious collection and weighing of material which 
flakes off in the course of the dissolution of the anode. The absolute current measurement was also employed by one of the authors of this work, in the determination of the electrochemical equivalents of benzoic acid and oxalic acid [14].

This communication reports only a small fraction of data obtained to date on the redetermination of the atomic weight of zinc. The primary purpose of this paper is to report the progress which has been made in this work. However, even at this point it is possible to present a significantly improved value of the atomic weight of zinc. Other available data which are not presented in this paper are in excellent agreement with the results reported here.

\section{Summary of Preliminary Investigations}

The nature and experimental detail of some preliminary investigations will be discussed in future publications. Nevertheless, it is germane to the subject at hand to outline the results of these preliminary studies here.

(1) The presence of oxygen (air) in the electrolyte has a significant effect on the rate of spontaneous corrosion of zinc. This in turn affects the experimentally determined electrochemical equivalent and the atomic weight of zinc. For this reason air was removed from the electrolyte be purging with nitrogen. A nitrogen atmosphere was maintained in the coulometer in all final determinations of the electrochemical equivalent of zinc.

(2) Commercial grade zincs without any a priori processing yield a higher electrochemical equivalent (on the order of $0.01 \%$ ) than the same materials subjected to vacuum fusion. This could easily be explained by the presence of gases (notably oxygen) in the commercial material which are removed under vacuum fusion conditions.

(3) Zinc anodes amalgamated on the surface undergo electrochemical dissolution without any detectable fall-off of material in the course of electrolysis.

(4) The difference between the free energies of the reaction

$$
\left.\mathrm{Zn}(\mathrm{Hg}) \rightarrow \mathrm{Zn}^{++}+2 e \mid \mathrm{U}^{\circ}=-0.799 \mathrm{~V}\right)
$$

and the next conceivable reaction

$$
\mathrm{Hg}+2 \mathrm{OH}^{-} \rightarrow \mathrm{HgO}+\mathrm{H}_{2} \mathrm{O}+2 e\left(\mathrm{U}^{\circ}=+0.098 \mathrm{~V}\right)
$$

is sufficiently large that even at current densities as high as several amperes per square centimeter the former reaction proceeds at 100.000 percent current efficiency. This was verified experimentally by measurements of the working anode potentials at different current densities, using first pure mercury anode and then zinc amalgam anodes. Coulometric experiments conducted at current densities ranging from $10^{-5}$ to $1.0 \mathrm{~A} \cdot \mathrm{cm}^{-2}$ substantiate this conclusion since no significant dependence between current density and the electrochemical equivalent of zinc could be found.
(5) Other investigated parameters include current (from $10^{-4}$ to $1.0 \mathrm{~A}$ ), time of electrolysis (from 3 to $7 \times 10^{4} \mathrm{~s}$ ), electrode area (from 0.5 to $10 \mathrm{~cm}^{2}$ ), total amount of change passed through the cell (up to $3 \times 10^{4} \mathrm{C}$ ), purity of material, and mass of dissolved zinc (up to $10 \mathrm{~g}$ ). Only the electrode area has a significant effect resulting from the dissolution of $\mathrm{ZnO}$ formed on the surface of the amalgam during handling of the electrode in air. The magnitude of this effect was evaluated $\left(10.7 \pm 1.5 \mu \mathrm{g} \mathrm{cm}^{-2}\right)$ and appropriate correction applied.

\section{Method}

The approach taken in this investigation is rather straightforward in its conception-to determine the mass of zinc dissolved anodically during the passage of a constant electrical current through the following electrochemical cell:

$$
\mathrm{Zn}(\mathrm{Hg}) \mid \mathrm{ZnCl}_{2} \text { (3 molal, aq), } \mathrm{NH}_{4} \mathrm{Cl}(25 \text { wt \%, aq) } \mid \mathrm{Hg} \text {. }
$$

The quantitative reaction which is of specific interest here is

$$
\mathrm{Zn}(\mathrm{Hg}) \rightarrow \mathrm{Zn}^{++}+2 e ;
$$

and the accompanying cathodic reaction is simply the reverse of reaction (1):

$$
\mathrm{Hg}+\mathrm{Zn}^{++}+2 e \rightarrow \mathrm{Zn}(\mathrm{Hg}) .
$$

In such a cell the composition of electrolyte remains unaltered throughout the whole experiment.

The passage of two faradays of charge through the cell dissolves $1 \mathrm{~mol}$ of zinc from zinc amalgam. The coulometric circuit enabling passage of charge through the cell within an accuracy of 0.0002 percent has been described earlier [14]. The coulometer used in this work is shown in figure 1. A weighed zinc amalgam anode is suspended in the coulometer (1). The mercury pool cathode (2) is located at the bottom of the coulometer. The ground glass flat joint (3) in the coulometer is provided for insertion of a porous membrane filter which is used in some experiments to establish the existence or the absence of any significant falloff of the material from the anode in the course of its electrochemical dissolution. The electrolyte is deaerated and a nitrogen atmosphere maintained in the coulometer throughout the experiment.

Zinc anodes are weighed by substitution on a $20 \mathrm{~g}$ capacity microbalance. The uncertainty of the mass measurement process (standard deviation) is $3 \times 10^{-6} \mathrm{~g}$. The smallest changes in the mass of $\mathrm{Zn}$ anodes in the experiments reported here were on the order of $2 \mathrm{~g}$.

A constant current of known magnitude is passed through the coulometer for a precalculated period of time sufficient to produce a desired change in mass of the anode roughly equivalent to the mass of a single weight in the calibrated set of weights (e.g. $2 \mathrm{~g}$ ). After termination of electrolysis, the zinc anode is carefully removed from the coulometer, washed first 


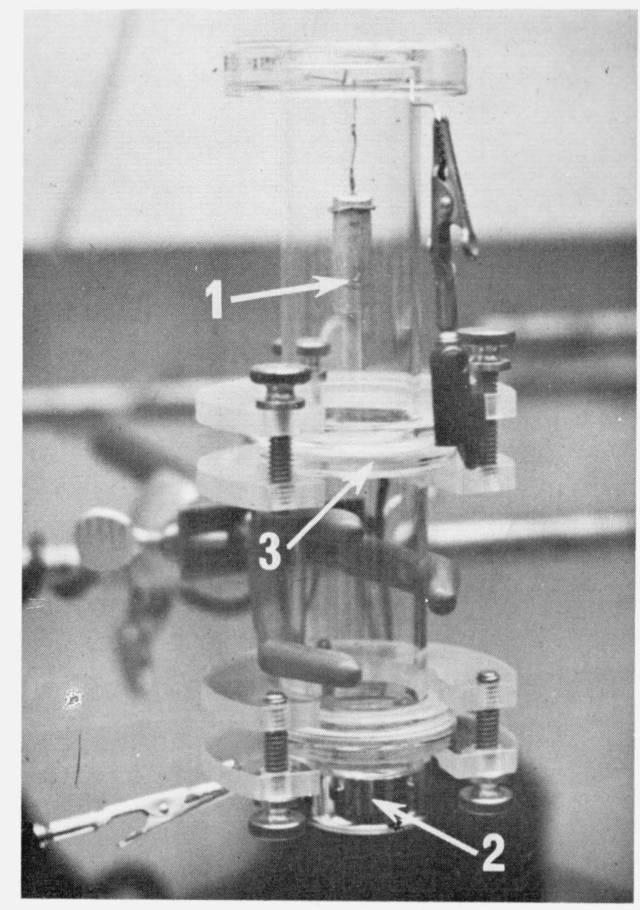

Figure 1. Coulometer for the determination of the atomic weight of zinc.

1 -zinc anode; 2 -mercury pool cathode; 3 -ground glass flat joint.

in 0.1 molar $\mathrm{NH}_{4} \mathrm{Cl}$ solution and then in hot distilled water and reweighed. Appropriate corrections for the effects of buoyancy of air are applied. Thus the charge to mass ratio can be readily computed.

\section{Results}

The results of experiments with metallic zinc samples of five different origins are summarized in the table. The first column in the table gives the original number of the experiment. Material code and the origin of material are given in columns two and three respectively. The last column, column four, gives the determined values of the atomic weight of zinc in each experiment.

The material designated as 1 is high purity zinc issued by the National Bureau of Standards as Standard Reference Material (SRM) 682. The material was produced by Cominco American, Inc. from a special lot of high-grade electrolytic zinc. It was purified by vacuum distillation, zone-refining and degasification. The overall assessment of impurities indicates that the material is 99.9999 percent $\mathrm{Zn} \mathrm{[15].} \mathrm{The} \mathrm{material}$ designated as 2 is a special high-grade metal $(99.995 \%$ $\mathrm{Zn})$ produced by the Electrolytic Zinc Company of Australasia Ltd. [16]. Materials 3, 4 and 5 were produced in Peru, Yugoslavia, and Italy respectively.

The calculated values of the atomic weight of zinc in column four are based on the coulometrically determined electrochemical equivalent of zinc and adopted value of the faraday. For the determination of charge consumed in the electrochemical reaction, the value of electrical current is based on the NBS ohm and U.S. legal volt of 1969.

Time measurement is based on $100 \mathrm{kHz}$ frequency maintained by NBS. Mass measurements were performed by substitution using a set of weights calibrated at NBS. The value of the faraday employed in these calculations is $96486.70 \mathrm{C} \mathrm{mol}^{-1}$ [17].

\section{Discussion}

The mean value of the atomic weight of zinc based on coulometric data reported here is 65.37736. A two-sided 95 percent confidence interval for the mean, 0.00086 , reflects adequately the uncertainty in this value due to the random sources of error. The accuracy of the result, however, depends not only on the random error of measurement, but also on the biases which could exist in the various stages of the measurement process and in the constants which are employed in calculation of the results.

The assessment of the uncertainties due to all known sources of possible systematic error (uncertainties in electrical standards, time, mass and the faraday) indicates that these sources can contribute as much as 0.002 percent $(0.00131 \mathrm{amu})$ error. Thus, the two components of error yields an uncertainty figure of 0.0022 in the atomic weight of zinc.

It is thus felt that on the basis of this work the atomic weight of zinc can be assigned the value

$$
65.377 \pm 0.003 \text {. }
$$

An the experimental values reported here lie well within the assigned uncertainty bounds. Further reduction in the uncertainty of this constant is anticipated when processing of all data is completed. Nevertheless, even the present uncertainty is an order of magnitude lower than that of the presently accepted value. (See table 1.)

On the basis of data presented here, there appears to be no significant difference between the values of atomic weight for materials of different origins even at the 10 percent level of significance. The published results of mass spectrometric investigations [7] also indicate no significant differences in the isotopic composition of zinc produced by electrolytic and chemical reduction processes. To insure that the value obtained in this research is truly representative of the terrestrial zinc, an experimental survey of primary zinc bearing minerals from world-wide sources is now in progress. This study is conducted on virgin minerals which have not been subjected to metallurgical processing (other than flotation), since the latter could produce isotope separation (isotope separation can conceivably occur in such processes as distillation which is commonly used in purification of zinc).

The authors express their gratitude to D. W. Kohis of The New Jersey Zinc Company, A. S. Gill of Elec- 
TABLE 1. Atomic weight of zinc determined by coulometry

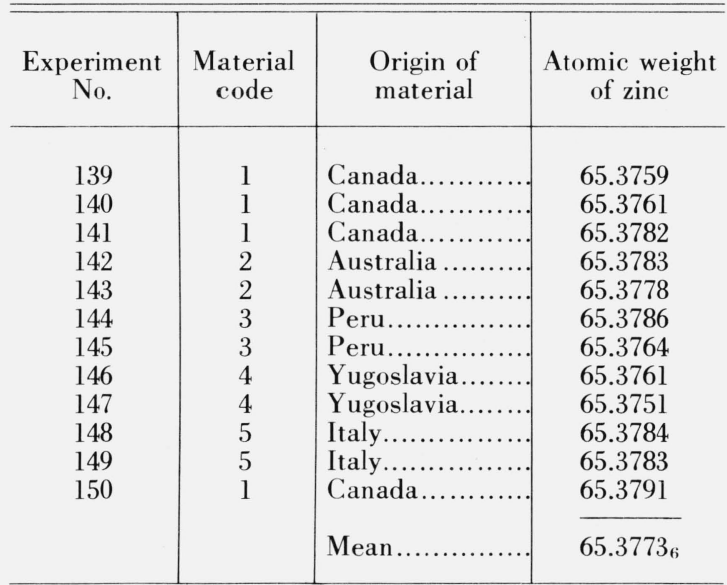

Pertinent Statistical Data

Standard deviation of a single determination $s=0.00134$.

Standard deviation of the mean $s / \sqrt{n}=0.00039$.

Two sided 95 percent confidences interval for the mean based on 11 degrees of freedom $t s / \sqrt{n}= \pm 0.00086$.

trolytic Zinc Company of Australasia Limited, W. Tunney, Jr. of St. Joseph Lead Company, and J. F. Harris of Cominco Limited for their donation of zinc samples from different origins. We also express our thanks to J. Mandel of the National Bureau of Standards for his help in statistical evaluation of our results and to A. R. Cook of International Lead Zinc Research Organization for his interest in this work.

\section{References}

[1] International Commission on Atomic Weights, Final Version of the Report 28-9-1967. Comptes Rendus XXIV IUPAC Conference, Prague, Sept. 4-10, 1967, pp. 130-141.

[2] IUPAC adopts new look in atomic weights, Chem. Eng. News 48, No. 4, 38 (1970).
[3] Hönigschmid, O., and von Mack, M., Des Atomgewicht des Zinks. Analyse des Zinkchlorids, Z. Anorg. Allgem. Chem. 246, 363 (1941)

[4] Baxter, G. P., and Grose, M. R., A revision of the atomic weight of zinc. The electrolytic determination of zinc in zinc bromide, J. Am. Chem. Soc. 38, 868 (1916).

[5] Baxter. G. P., and Hodges. J. H., A revision of the atomic weight of zinc. II. The electrolytic determination of zinc in zinc chloride, J. Am. Chem. Soc. 43, 1242 (1921).

[6] Leland, W. T., and Nier, A. O., The relative abundances of the zinc and cadmium isotopes, Phys. Rev. 73, 1206 (1948).

[7] Hess, D. C., Inghram, M. G., and Hayden, R. J., The relative abundance of zinc isotopes, Phys. Rev. 74, 1531 (1948).

[8] Cameron, A. E., and Wichers, E., Report of the International Commission on Atomic Weights (1961), J. Am. Chem. Soc. 84, 4175 (1962).

[9] Faraday, M., Identity of electricities derived from different sources, Phil. Trans. Series 2, 3, 23 (1833).

[10] Laird, J. S., and Hulett, G. A., The electrochemical equivalent of cadmium, Trans. Am. Electrochem. Soc. 22, 385 (1913).

[11] Gladstone, J. H., and Hibbert W., On the atomic weight of zinc, J. Chem. Soc. 55, 443 (1889).

[12] Hamer, W. J., Resumé of values of the Faraday, J. Res. Nat. Bur. Stand. (U.S.) 72A, (Phys. and Chem.), No. 4, 435 (1968).

[13] Craig, D. N., Hoffman, J. I., Law, C. A., and Hamer, W. J., Determination of the value of the faraday with a silverperchloric acid coulometer, J. Res. Nat. Bur. Stand. (U.S.) 64A, (Phys. and Chem.), No. 1, 381 (1960).

[14] Marinenko, G., and Taylor, J. K., Electrochemical equivalents of benzoic and oxalic acid, Anal. Chem. 40, 1645 (1968).

[15] This high purity standard reference material, SRM No. 682, is available from the Office of Standard Reference Materials, National Bureau of Standards. Washington, D.C. 20234. along with the Certificate of Analysis at a unit price of $\$ 90$.

[16] Gill, A. S., Acting General Superintendent of Electrolytic Zinc Company of Australasia Ltd., Private Communication.

[17] Taylor, B. N., Parker, W. H., and Langenberg, D. N., Determination of $e / h$, using macroscopic quantum phase coherence in superconductors: implications for quantum electrodynamics and the fundamental phyical constants, Rev. Mod. Phys. 41, 375 (1969).

(Paper 75A6-687) 